\title{
Comparison of Serum Lipid Profile between Gestational Diabetes Mellitus and Pregnant Women with Normal Glucose Tolerance
}

\author{
Mahmudul Hossain ${ }^{*}$, A. K. M. Shahidur Rahman'2, Samira Mahjabeen ${ }^{3}$, Mohona Zaman", \\ Mohaiminul Abedin', Tahseen Mahmood6, Md. Abdur Razzaque7, Ummul Khair Alam ${ }^{8}$ \\ ${ }^{1}$ Department of Medicine, Kurmitola General Hospital, Dhaka, Bangladesh \\ ${ }^{2}$ Department of Nephrology, Bangabandhu Sheikh Mujib Medical University (BSMMU), Dhaka, Bangladesh \\ ${ }^{3}$ Department of Endocrinology, Bangabandhu Sheikh Mujib Medical University (BSMMU), Dhaka, Bangladesh \\ ${ }^{4}$ Department of Endocrinology, Monno Medical College Hospital, Manikganj, Bangladesh \\ ${ }^{5}$ Department of Anatomy, Abdul Malek Ukil Medical College, Noakhali, Bangladesh \\ ${ }^{6}$ Department of Endocrinology, BRB Hospital Limited, Dhaka, Bangladesh \\ ${ }^{7}$ Department of Dermatology, Khwaja Yunus Ali Medical College and Hospital (KYAMCH), Sirajganj, Bangladesh \\ ${ }^{8}$ Department of Maternal and Child Health (MCH), National Institute of Preventive and Social Medicine (NIPSOM), Dhaka, \\ Bangladesh \\ Email: *mahmudulhossain@hotmail.com
}

How to cite this paper: Hossain, M., Rahman, A.K.M.S., Mahjabeen, S., Zaman, M., Abedin, M., Mahmood, T., Razzaque, Md.A. and Alam, U.K. (2020) Comparison of Serum Lipid Profile between Gestational Diabetes Mellitus and Pregnant Women with Normal Glucose Tolerance. Journal of Biosciences and Medicines, 8, 148-159. https://doi.org/10.4236/jbm.2020.86014

Received: April 20, 2020

Accepted: June 13, 2020

Published: June 16, 2020

Copyright $\odot 2020$ by author(s) and Scientific Research Publishing Inc. This work is licensed under the Creative Commons Attribution International License (CC BY 4.0).

http://creativecommons.org/licenses/by/4.0/ (c) (i) Open Access

\section{Abstract}

Background: Aberrant lipid metabolism presumed to have important relationship with gestational diabetes mellitus (GDM), though previous studies revealed inconsistent results on this area. Objectives: To identify the difference of serum lipid profile between gestational diabetes mellitus (GDM) and pregnant woman with normal glucose tolerance (NGT). Methods: This cross sectional study was conducted from January 2017 to December 2017 at Department of Endocrinology, Bangabandhu Sheikh Mujib Medical University (BSMMU), Dhaka, Bangladesh with $31 \mathrm{GDM}$ and equal number of NGT pregnant women diagnosed on the basis of WHO criteria-2013, during 24 40 weeks of gestation. Glucose was measured by glucose oxidase method and fasting serum lipid profile [Total cholesterol (TC), High Density Lipoprotein-cholesterol (HDL-C) and Triglyceride (TG)] was measured by enzymatic-colorimetric method. Data were analyzed and compared by statistical tests. Results: Among total sixty-two (62) study subjects, 31 were GDM (age: 27.52 \pm 4.8 years, body mass index (BMI): $27.17 \pm 3.3 \mathrm{~kg} / \mathrm{m}^{2}$ ) and 31 were pregnant women with NGT (age: $24.94 \pm 4.2$ years, BMI: $25.43 \pm 6.5 \mathrm{~kg} / \mathrm{m}^{2}$ ). Mean age of GDM group was significantly higher than that of NGT group $(\mathrm{p}=0.028)$. Women with GDM showed relatively higher BMI than NGT women but that was not statistically significant $(p=0.194)$. Fasting lipid profiles between GDM
\end{abstract}


and NGT (GDM vs. NGT; total cholesterol: $194.21 \pm 42.18$ vs. $208.52 \pm 42.18$ $\mathrm{mg} / \mathrm{dl}, \mathrm{p}=0.187$; HDL-C: $47.50 \pm 16.17$ vs. $47.18 \pm 11.71 \mathrm{mg} / \mathrm{dl}, \mathrm{p}=0.928$; LDL-C: $109.25 \pm 28.80$ vs. $119.30 \pm 34.76 \mathrm{mg} / \mathrm{dl}, \mathrm{p}=0.220$ and triglyceride $204.78 \pm 58.50$ vs. $202.34 \pm 79.18 \mathrm{mg} / \mathrm{dl}, \mathrm{p}=0.891$ ) were not significantly different. The variations in all lipid fraction values were not statistically significant among GDM women when analyzed between BMI groups holding BMI cut-off at $23 \mathrm{~kg} / \mathrm{m}^{2}$. No significant differences of any values of lipid profile were found in GDM women according to various age categories (Age $<25$ years vs. $\geq 25$ years). Conclusions: Lipid profile does not differ between women with GDM and pregnant woman with NGT.

\section{Keywords}

Gestational Diabetes Mellitus (GDM), Normal Glucose Tolerance (NGT), Serum Lipid Profile

\section{Introduction}

Gestational diabetes mellitus (GDM) is an abnormal glucose tolerance that is the first time detected during pregnancy, and is the most common medical and metabolic complication of pregnancy [1]. The prevalence of GDM is increasing worldwide and $15 \%$ to $22 \%$ of all pregnancies are affected by GDM; this prevalence may be higher under new diagnostic criteria [2]. GDM could be associated with many consequences, such as fetal macrosomia, preeclampsia and high cesarean section rate [3] [4]. Women with GDM and their offspring are at risk for later development of obesity, type 2 diabetes mellitus and cardiovascular disorders [5] [6]. GDM is a heterogeneous disorder in which age, obesity, and genetic background contribute to the severity of the disease [7]. The hallmark of this condition is increased insulin resistance (IR) [8] [9]. Insulin resistance occurs in pregnant women due to hormonal changes. Maternal hormones interfere with the action of insulin. As a result, glucose level is increased in blood with excess insulin produced in GDM to overcome this resistance in a normal pregnancy [8] [9].

It has been reported that lipid level increases slightly in early pregnancy, but significantly in later pregnancy and maternal dyslipidemia which elevated over a physiologic range is a common phenomenon of pregnancy [10]. Hyperlipidemia is commonly detected in the $2^{\text {nd }}$ half of pregnancy, which is regarded as a physiologically required mechanism to provide metabolic fuel and nutrients for the fetus [11]. However, it still remains obscure to ascertain which level of lipid elevation is physiologic or pathologic.

Lipid profile consists of serum Total cholesterol (TC), High Density Lipoprotein-cholesterol (HDL-C), Low Density Lipoprotein-cholesterol (LDL-C) and Triglyceride (TG). Several factors in the body are responsible for the differences of these components in the body. Lipid profiles differ in people of different gend- 
ers, ages, activity levels, overall health, smoking status and glucose levels in the body, which can forecast the presence of various conditions including diabetes mellitus [10]. Therefore serum lipid profile is important in the assessment of blood glucose levels. The abnormalities of carbohydrate metabolism observed in GDM may affect other metabolic pathways especially lipid metabolism [12]. IR which is one of the primary defects in majority of GDM presumed to have important relationship with dyslipidaemia in pregnancy and future cardio-metabolic risk [13].

Early pregnancy dyslipidemia is associated with the risk of developing GDM [13] [14]. GDM is accompanied by alterations in fasting, postprandial, and integrated 24 hours of plasma concentrations of amino acids, glucose, and lipids [15]. GDM is associated with hyperlipidaemia which has evident by the significantly elevated total cholesterol and triglyceride concentrations [5] [16] [17]. Significant increase in serum cholesterol, serum triglyceride and serum very low density lipoprotein (VLDL) levels were found in cases with gestational diabetes when compared to healthy pregnant women [18]. It has been reported that pregnancy and diabetes have additive effect on the development of an atherogenic lipid profile [19].

It has been suggested that abnormal glucose levels, glycosylated hemoglobin (HbAlc), serum cholesterol, and serum triglycerides play an important role in pathophysiology of gestational diabetes [20]. Circulating lipid levels in GDM versus normal pregnancy have been extensively studied, but results were less consistent with most studies focusing on the third trimester [21]. Still there are considerable controversies as to whether lipid patterns differ in women with GDM early in pregnancy and whether these early patterns are potential markers of preexisting insulin resistance [22]. In this study, we were comparing measurements of total cholesterol, triglycerides, low-density lipoprotein cholesterol (LDL-C) and high-density lipoprotein cholesterol (HDL-C), in the second and third trimesters of pregnancy in women who developed GDM and those who remain glucose tolerant. Early diagnosis of gestational diabetes and appropriate measures against dislipidemia will decrease adverse neonatal and maternal outcomes.

\section{Material and Methods}

This prospective cross sectional study was conducted at Department of Endocrinology, Bangabandhu Sheikh Mujib Medical University (BSMMU), Dhaka, Bangladesh from January 2017 to December 2017. The study was approved by the Ethical Review Committee, BSMMU, Dhaka, Bangladesh. According to the statistical calculation, this study comprised of sixty two (62) subjects [31 GDM women, diagnosed by the WHO 2013 criteria as cases and 31 healthy pregnant women (NGT) as control subjects)] [9]. The study population had been recruited from pregnant women attending the antenatal clinic and GDM clinic of Bangabandhu Sheikh Mujib Medical University, following selection criteria. Women 
in 24 - 40 weeks of gestation with singleton pregnancy age between 18 to 35 years were screened and enrolled consecutively in this study. Pregnant women with overt diabetes, history of taking oral antidiabetic agents, diabetes mellitus in pregnancy (DIP), patient with other co-morbid diseases (hepatic, renal or thyroid disorders, chronic infections etc.) were excluded from the study. Informed written consent was taken from each participant prior to enrollment in the study. Each pregnant women had been challenged by 75 gm glucose (75 gm in $300 \mathrm{ml}$ of water) following an overnight fast for oral glucose tolerance test (OGTT), as the test fulfilled the diagnostic criteria of GDM as set by $\mathrm{WHO}$, they were enrolled as GDM. Healthy pregnant women with normal OGTT (NGT) were served as control subjects. Demographic, anthropometrics, family history and other related information of each study subject were recorded in a data collection sheet. Measurement of serum fasting total Cholesterol, LDL-cholesterol, HDL-cholesterol and Triglyceride of selected subjects was done from fasting serum samples obtained during OGTT. Glucose was measured by glucose oxidase method and fasting serum lipid profile (Total cholesterol, TG and HDL-c) was measured by enzymatic-colorimetric method. All biochemical tests were performed at the Biochemistry and Molecular Biology Laboratory, Department of Biochemistry and Molecular Biology, BSMMU, Dhaka, Bangladesh. The differences within variables between the groups were analyzed and compared.

\subsection{Gestational Diabetes Mellitus}

Gestational diabetes mellitus had been diagnosed by the WHO 2013 criteria if any one of the following criteria was met irrespective of gestational age:

- Fasting plasma glucose $=5.1-6.9 \mathrm{mmol} / \mathrm{l}(92-125 \mathrm{mg} / \mathrm{dl})$;

- 1 -h post $75 \mathrm{~g}$ oral glucose load $\geq 10.0 \mathrm{mmol} / \mathrm{l}(180 \mathrm{mg} / \mathrm{dl})$;

- 2-h post $75 \mathrm{~g}$ oral glucose load = $8.5-11.0 \mathrm{mmol} / \mathrm{l}(153-199 \mathrm{mg} / \mathrm{dl})$.

\subsection{Body Mass Index [BMI $\left.\left(\mathrm{kg} / \mathrm{m}^{2}\right)\right]$}

BMI of the subjects was calculated using standard formula, BMI = Weight $(\mathrm{kg}) /[\text { Height }(\mathrm{m})]^{2}$. BMI was classified according to WHO and nutritional status based on "Asian criteria" values [23].

\begin{tabular}{ccc}
\hline Nutritional Status & $\begin{array}{c}\text { WHO criteria } \\
\text { (BMI cut-off) }\end{array}$ & $\begin{array}{c}\text { “Asian criteria” } \\
\text { (BMI cut-off) }\end{array}$ \\
\hline Underweight & $<18.5$ & $<18.5$ \\
Normal weight & $18.5-24.9$ & $18.5-22.9$ \\
Overweight & $25-29.9$ & $23-24.9$ \\
Pre-Obese & - & $25-29.9$ \\
Obese & $\geq 30$ & $\geq 30$ \\
Obese Type-1 (obese) & $30-40$ & $30-40$ \\
Obese Type-2 (morbid obese) & $40.1-50$ & $40.1-50$ \\
Obese Type-3 (super obese) & $>50$ & $>50$ \\
\hline
\end{tabular}




\subsection{Dyslipidemia}

Dyslipidemia was defined according to the American Heart Association, if Total cholesterol: $>200 \mathrm{mg} / \mathrm{dl}$ or HDL-cholesterol: $<35 \mathrm{mg} / \mathrm{dl}$ or LDL-cholesterol: >130 $\mathrm{mg} / \mathrm{dl}$ or Triglyceride: $>150 \mathrm{mg} / \mathrm{dl}$.

\subsection{Statistical Analysis}

Data cleaning validation and analysis were performed using the Statistical Package for Social Science (SPSS) software for Windows version-22. Results were described in frequencies or percentages for qualitative values and mean \pm SD for quantitative values with normal distribution. Subgroups made on the basis of clinical and biochemical findings were compared by unpaired student's t-test or Chi square test $/ \chi^{2}$-test as applicable. $\mathrm{p}$ Value $\leq 0.05$ was considered as statistically significant.

\section{Results}

In an attempt to compare fasting lipid profile between GDM and pregnant women with NGT; 62 pregnant women (age: $26.23 \pm 4.70$ years, BMI: $26.3 \pm 5.20$ $\mathrm{kg} / \mathrm{m}^{2}$; mean $\pm \mathrm{SD}$ ) were encompassed in this study. All pregnant women were screened by 3-sample of OGTT following WHO 2013 criterion to include 31 women with GDM (age: $27.52 \pm 4.80$ years, BMI: $27.17 \pm 3.30 \mathrm{~kg} / \mathrm{m}^{2}$; mean \pm SD) and equal number of women with NGT (age: $24.94 \pm 4.20$ years, BMI: 25.43 $\pm 6.50 \mathrm{~kg} / \mathrm{m}^{2}$; mean $\pm \mathrm{SD}$ ).

\subsection{Glucose Profile of the Study Subjects}

Table 1 displays the plasma glucose (PG) profile of study subjects. PG values during 75 gm OGTT were significantly higher in GDM at all time points (GDM vs. NGT; 0-h PG: $5.36 \pm 0.44$ vs. $4.51 \pm 0.32$; 01-h PG: $9.8 \pm 1.42$ vs. $7.46 \pm 1.2$; and $02-\mathrm{h}$ PG: $8.27 \pm 1.45$ vs. $6.6 \pm 1.06 \mathrm{mmol} / \mathrm{L}$, mean $\pm \mathrm{SD}$; $\mathrm{p}<0.001$ for all values).

\subsection{Baseline Characteristics of the Study Subjects}

Mean $( \pm \mathrm{SD})$ age of GDM group was significantly higher than the mean $( \pm \mathrm{SD})$ age of NGT group (GDM vs. NGT; $27.52 \pm 4.8$ years and $24.94 \pm 4.2$ years, $\mathrm{p}=$ 0.028 ). Women with GDM showed relatively higher BMI (GDM vs. NGT; 27.17 $\pm 3.3 \mathrm{~kg} / \mathrm{m}^{2}$ vs. $25.43 \pm 6.5 \mathrm{~kg} / \mathrm{m}^{2}, \mathrm{p}=0.194$; mean $\pm \mathrm{SD}$ ) than NGT women but that was not statistically significant. Frequency of GDM was also significantly higher in service holder (GDM vs. NGT; $45.2 \%$ vs. $19.4 \%, \mathrm{p}=0.029$ ). Gestational age (GDM vs. NGT; $29.77 \pm 4.09$ week vs. $28.81 \pm 4.64$ week, $\mathrm{p}=0.388$; mean \pm $\mathrm{SD}$ ), previous history of GDM [GDM vs. NGT; 2 (66.7\%) vs. 1 (33.3\%), p = 0.554 ] or family history of DM in $1^{\text {st }}$ degree relative [GDM vs. NGT; 14 (58.3\%) vs. 10 (41.7\%), $\mathrm{p}=0.297$ ] were not significantly different between the groups, however values of these variables were relatively high among GDM women (Table 2). 
Table 1. Glucose profile of the study subjects during 75 gm OGTT ${ }^{\star}(n=62)$.

\begin{tabular}{cccc}
\hline $\begin{array}{c}\text { OGTT glucose values } \\
(\mathrm{mmol} / \mathrm{L})\end{array}$ & $\begin{array}{c}\text { Plasma glucose of GDM } \\
(\mathbf{n}=31) \\
\text { Mean } \pm \mathrm{SD}\end{array}$ & $\begin{array}{c}\text { Plasma glucose of NGT } \\
(\mathrm{n}=31) \\
\text { Mean } \pm \mathrm{SD}\end{array}$ & $\mathrm{p}$ \\
\hline 0-h plasma glucose & $5.36 \pm 0.44$ & $4.51 \pm 0.32$ & $<0.001^{*}$ \\
01-h plasma glucose & $9.8 \pm 1.42$ & $7.46 \pm 1.2$ & $<0.001^{*}$ \\
02-h plasma glucose & $8.27 \pm 1.45$ & $6.6 \pm 1.06$ & $<0.001^{*}$ \\
\hline
\end{tabular}

p Values obtained by Student's t-test; OGTT: oral glucose tolerance test, [ ${ }^{*}$ Glycated hemoglobin (HbA1c) was not used for diagnosing gestational diabetes]; GDM: gestational diabetes mellitus; NGT: normal glucose tolerance; ${ }^{*}$ significant.

Table 2. Baseline characteristics of the study subjects $(n=62)$.

\begin{tabular}{cccc}
\hline Variables & GDM & NGT & p \\
\hline & $\mathbf{n}=31$ & $\mathbf{n}=31$ & \\
\hline Age (years, mean \pm SD) & $27.52 \pm 4.8$ & $24.94 \pm 4.2$ & $0.028^{\star}$ \\
Occupation & & & \\
Housewife & $15(58.1 \%)$ & $20(64.5 \%)$ & $0.200^{\text {ns }}$ \\
Service & $14(45.2 \%)$ & $6(19.4 \%)$ & $0.029^{*}$ \\
Others & $2(6.5 \%)$ & $5(16.1 \%)$ & $0.228^{\text {ns }}$ \\
BMI kg/m ${ }^{2}$, (mean \pm SD) & $27.17 \pm 3.3$ & $25.43 \pm 6.5$ & $0.194^{\text {ns }}$ \\
Gestational weeks at detection (mean \pm SD) & $29.77 \pm 4.09$ & $28.81 \pm 4.64$ & $0.388^{\text {ns }}$ \\
Previous history of GDM & $2(66.7 \%)$ & $1(33.3 \%)$ & $0.554^{\text {ns }}$ \\
Family history of DM in $1^{\text {st }}$ degree relatives & $14(58.3 \%)$ & $10(41.7 \%)$ & $0.297^{\text {ns }}$ \\
\hline
\end{tabular}

Significance values stand for comparison between GDM and NGT groups by Student's t-test and $\chi^{2}$-test; BMI: body mass index; GDM: gestational diabetes mellitus; NGT: normal glucose tolerance; DM: diabetes mellitus; ${ }^{*}$ significant; ns: not significant.

\subsection{Fasting Lipid Profile in GDM and NGT}

Table 3 shows the mean $( \pm S D)$ difference of fasting lipid profile between GDM and NGT. It was observed that there was no statistically significant difference between the GDM and NGT groups in concentrations of various lipid fractions (GDM vs. NGT; Total cholesterol: $194.21 \pm 42.18 \mathrm{mg} / \mathrm{L}$ vs. $208.52 \pm 42.18 \mathrm{mg} / \mathrm{L}$, $\mathrm{p}=0.187$, HDL-C: $47.50 \pm 16.17 \mathrm{mg} / \mathrm{L}$ vs. $47.18 \pm 11.71 \mathrm{mg} / \mathrm{L}, \mathrm{p}=0.928$, LDL-C: $109.25 \pm 28.80 \mathrm{mg} / \mathrm{L}$ vs. $119.30 \pm 34.76 \mathrm{mg} / \mathrm{L}, \mathrm{p}=0.220$ and Triglyceride: 204.78 $\pm 58.50 \mathrm{mg} / \mathrm{L}$ vs. $202.34 \pm 79.18 \mathrm{mg} / \mathrm{L}, \mathrm{p}=0.891)$.

\subsection{Lipid Profile in GDM under BMI at Cut-off $23 \mathrm{~kg} / \mathrm{m}^{2}$}

As depicted in Table 4, all lipid fraction values between GDM group with BMI < $23 \mathrm{~kg} / \mathrm{m}^{2}$ and GDM with BMI $\geq 23 \mathrm{~kg} / \mathrm{m}^{2}$ were not significantly different (BMI: $<23 \mathrm{~kg} / \mathrm{m}^{2}$ vs. $\geq 23 \mathrm{~kg} / \mathrm{m}^{2}$; total cholesterol: $210.85 \pm 39.52 \mathrm{mg} / \mathrm{L}$ vs. $193.06 \pm$ $42.77 \mathrm{mg} / \mathrm{L}, \mathrm{p}=0.573$; HDL-C: $34.24 \pm 11.22 \mathrm{mg} / \mathrm{L}$ vs. $48.41 \pm 16.19 \mathrm{mg} / \mathrm{L}, \mathrm{p}=$ 0.237; LDL-C: $126.27 \pm 1.44 \mathrm{mg} / \mathrm{L}$ vs. $108.08 \pm 29.43 \mathrm{mg} / \mathrm{L}, \mathrm{p}=0.397$ and triglyceride: $187.46 \pm 13.18 \mathrm{mg} / \mathrm{L}$ vs. $205.97 \pm 60.31 \mathrm{mg} / \mathrm{L}, \mathrm{p}=0.673$ ). Although total cholesterol, LDL-C levels were relatively high and HDL-C level was compara- 
tively low in GDM with BMI $<23 \mathrm{~kg} / \mathrm{m}^{2}$, while triglyceride level was relatively high in GDM with BMI $\geq 23 \mathrm{~kg} / \mathrm{m}^{2}$.

\subsection{Lipid Profile in GDM under Age at Cut off 25 Years}

A cut-off age was set at 25 years, as age $\geq 25$ years considered a risk factor for GDM [24]. GDM women with age $<25$ years or $\geq 25$ years had no statistically significant differences of any value of lipid profile (age $<25$ years vs. $\geq 25$ years; total cholesterol: $207.38 \pm 50.51 \mathrm{mg} / \mathrm{L}$ vs. $190.36 \pm 39.83 \mathrm{mg} / \mathrm{L}, \mathrm{p}=0.356$; HDL-C: $46.74 \pm 13.65 \mathrm{mg} / \mathrm{L}$ vs. $47.72 \pm 17.09 \mathrm{mg} / \mathrm{L}, \mathrm{p}=0.890$; LDL-C: $113.08 \pm$ $30.88 \mathrm{mg} / \mathrm{L}$ vs. $108.13 \pm 28.76 \mathrm{mg} / \mathrm{L}, \mathrm{p}=0.696$ and triglyceride: $226.83 \pm 70 \mathrm{mg} / \mathrm{L}$ vs. $198.35 \pm 74.72 \mathrm{mg} / \mathrm{L}, \mathrm{p}=0.264)$ (Table 5$)$.

Table 3. Lipid profile in GDM and NGT $(\mathrm{n}=62)$.

\begin{tabular}{cccc}
\hline $\begin{array}{c}\text { Variables } \\
(\mathrm{mg} / \mathrm{dl})\end{array}$ & $\begin{array}{c}\text { GDM } \\
(\mathbf{n}=31)\end{array}$ & $\begin{array}{c}\text { NGT } \\
(\mathbf{n}=31)\end{array}$ & $\mathbf{P}$ \\
\hline Total cholesterol & $194.21 \pm 42.18$ & $208.52 \pm 42.18$ & $0.187^{\mathrm{ns}}$ \\
HDL-C & $47.50 \pm 16.17$ & $47.18 \pm 11.71$ & $0.928^{\mathrm{ns}}$ \\
LDL-C & $109.25 \pm 28.80$ & $119.30 \pm 34.76$ & $0.220^{\mathrm{ns}}$ \\
Triglyceride & $204.78 \pm 58.50$ & $202.34 \pm 79.18$ & $0.891^{\mathrm{ns}}$ \\
\hline
\end{tabular}

Comparison between groups was done by Student's t test; GDM: gestational diabetes mellitus; NGT: normal glucose tolerance; HDL-C: high density lipoprotein-cholesterol; LDL-C: low density lipoprotein-cholesterol; ns: not significant.

Table 4. Lipid profile in GDM according to BMI categories (cut-off $\left.23 \mathrm{~kg} / \mathrm{m}^{2}\right)(\mathrm{n}=31)$.

\begin{tabular}{|c|c|c|c|}
\hline \multirow[b]{2}{*}{ Variables } & \multicolumn{2}{|c|}{ Groups } & \multirow[b]{2}{*}{$\mathbf{P}$} \\
\hline & $\begin{array}{c}\text { BMI }<23\left(\mathrm{~kg} / \mathrm{m}^{2}\right) \\
(\mathrm{n}=2)\end{array}$ & $\begin{array}{c}\text { BMI } \geq 23\left(\mathrm{~kg} / \mathrm{m}^{2}\right) \\
(\mathrm{n}=29)\end{array}$ & \\
\hline Total cholesterol & $210.85 \pm 39.52$ & $193.06 \pm 42.77$ & $0.573^{\text {ns }}$ \\
\hline HDL-C & $34.24 \pm 11.22$ & $48.41 \pm 16.19$ & $0.237^{\mathrm{ns}}$ \\
\hline LDL-C & $126.27 \pm 1.44$ & $108.08 \pm 29.43$ & $0.397^{\mathrm{ns}}$ \\
\hline Triglyceride & $187.46 \pm 13.18$ & $205.97 \pm 60.31$ & $0.673^{\text {ns }}$ \\
\hline
\end{tabular}

Comparison between groups done by Student's t test; ns: not significant; GDM: gestational diabetes mellitus; BMI: body mass index; HDL-C: high density lipoprotein-cholesterol; LDL-C: low density lipoprotein-cholesterol.

Table 5. Lipid profile in GDM according to age categories (cut-off 25 years) $(n=31)$.

\begin{tabular}{cccc}
\hline & \multicolumn{2}{c}{ Groups } & \multirow{2}{*}{$\mathbf{P}$} \\
\cline { 2 - 3 } Variables & $\begin{array}{c}\text { Age }<25 \text { years } \\
(\mathbf{n}=7)\end{array}$ & $\begin{array}{c}\text { Age } \geq 25 \text { years } \\
(\mathbf{n}=\mathbf{2 4})\end{array}$ & \\
\hline Total cholesterol & $207.38 \pm 50.51$ & $190.36 \pm 39.83$ & $0.356^{\mathrm{ns}}$ \\
HDL-C & $46.74 \pm 13.65$ & $47.72 \pm 17.09$ & $0.890^{\mathrm{ns}}$ \\
LDL-C & $113.08 \pm 30.88$ & $108.13 \pm 28.76$ & $0.696^{\mathrm{ns}}$ \\
Triglyceride & $226.83 \pm 70$ & $198.35 \pm 74.72$ & $0.264^{\mathrm{ns}}$ \\
\hline
\end{tabular}

Comparison between groups done by Student's $\mathrm{t}$ test; ns: not significant; GDM: gestational diabetes mellitus; HDL-C: high density lipoprotein-cholesterol; LDL-C: low density lipoprotein-cholesterol. 


\section{Discussions}

Although pregnancy is a condition characterized by progressive insulin resistance (IR), GDM develops in only a small proportion of pregnant women [8]. This physiological IR underlies all pregnancies usually start to appear around 24 - 28 weeks of gestation and progressing through the third trimester of pregnancy. Failure of $\beta$-cell compensation for pregnancy induced IR results in carbohydrate intolerance by which GDM is diagnosed. Moreover women with GDM are increased risk of developing metabolic dysfunction including hyperlipidaemia after pregnancy. Therefore present study was conducted to observe the changes in lipid profile in GDM and women without glucose aberrance.

Aberrant lipid metabolism in normal pregnancy are characterized by marked elevations of total cholesterol and triglyceride (TG) levels as a result of increased liver synthesis of TG in response to elevated estrogen levels. Reduction of lipoprotein lipase (LPL) activity due to the down regulation of LPL gene expression by estrogen during pregnancy decreases the clearance of lipids [13]. Maternal factors such as BMI, overweight, maternal nutrition, pre-pregnancy lipid levels and various medical complications of pregnancy may also have significant effects on lipid metabolism and plasma lipid levels [13]. In this study it was intended to explore the discrepancy of fasting lipid profile between GDM and pregnancy without glucose abnormality. It was demonstrated that various fractions of lipid profile were not significantly differ between women with GDM and pregnant women with normal glucose tolerance. This finding was consistent with a study where fractions of lipid profile (TG, TC, LDL-C and HDL-C) did not vary between pregnant women with GDM and those without GDM [25]. Lipid parameters were significantly higher in women with GDM than pregnant women with NGT that found in different studies which differ from this current study [9] [26] [27]. Fat storage increases in the second trimester of pregnancy leading to increase plasma TG. LDL-C is formed from VLDL which is principal transport form of TG in the blood. So in GDM when TG concentration increases, LDL-C increases accordingly. In this study, Triglycerides concentration was increased but LDL-C was within normal limit in both GDM and pregnant women with NGT. These results were not consistent with a previous population-based study as reported that LDL-C was significantly higher during normal pregnancy and also in GDM [28]. The results of increased TG level, unchanged HDL-C level and decreased total cholesterol level in GDM compared with pregnant women with NGT obtained from our study were consistent with results of a previous study where similar findings were observed [29]. Besides, increasing maternal age and BMI are classically considered as risk factors for GDM [24] [30] [31]. The present study also noted older age and higher BMI in GDM women compared to NGT women. Previous history of GDM and family history of diabetes was found to be higher among GDM women in this study, these observations were also an agreement with previous studies [24] [30] [31].

Fasting Lipid profile and GDM have been shown to be the important predic- 
tors for maternal metabolic disturbances including dyslipidemia, hypertension and cardiovascular disease [12]. Moreover, pre-pregnancy BMI was found to have a far greater effect on IR in pregnancy in Asian women than Caucasians [32]. Besides maternal weight gain, nutrition and pre-pregnancy lipid levels are known to have significant effects on lipid metabolism and plasma lipid levels during pregnancy [13]. Well recognized risk factors for GDM include overweight and obesity [33]. In this study, variables were analyzed among GDM women holding BMI cut-off at $23 \mathrm{~kg} / \mathrm{m}^{2}$. In this series, no significant abnormalities were observed in all values of lipid profile among GDM group under BMI cut off $23 \mathrm{~kg} / \mathrm{m}^{2}$. HDL-cholesterol level was relatively lower in GDM $<23 \mathrm{~kg} / \mathrm{m}^{2}$ than $\geq 23 \mathrm{~kg} / \mathrm{m}^{2}$. This result was consistent with other studies where HDL-C was found lower in GDM under BMI cut off $<25 \mathrm{~kg} / \mathrm{m}^{2}$ [34] [35]. In accordance with some other studies a cut-off of age was set at 25 years; and lipid profile was analyzed in GDM group with age $<25$ years and $\geq 25$ years [24]. In our study among GDM women with age $<25$ years or $\geq 25$ years, did not shown any statistically significant differences in all values of lipid profile even in its different fractions like total cholesterol, HDL-C, LDL-C and triglyceride. These findings were consistent with previous report where no significant abnormality was found between the maternal age and lipid parameters [9].

To summarize, this study demonstrated that older age and higher BMI in GDM women compared to NGT women, but lipid profile do not differ between women with GDM and pregnancy without glucose aberration. This result is consistent with the previous reports where it was shown that, when BMI and gestational age are taken into account, dyslipidemia is not significantly associated with GDM. Impact of dyslipidemia on pregnancy outcomes and future development of type 2 diabetes in GDM should be addressed in long term prospective studies.

\section{Conclusion}

This study concluded that lipid profiles do not differ between women with GDM and pregnancy without glucose aberration. Further studies are warranted to elucidate the role of dyslipidemia in the pathogenesis of GDM.

\section{Limitations}

It was a single centre study with a relatively small sample size. Lipid profile of study subjects could not be compared in different trimester of pregnancy due to financial and time constrains. Baseline characteristics such as pre-pregnancy BMI and pre-pregnancy lipid profile could not be used for comparison between the study subjects.

\section{Recommendations}

Further studies including large sample size and various lipid fractions (free fatty acid, Apo-B: Apo-A ratio etc.) are required to determine dyslipidemia in GDM. 


\section{Conflicts of Interest}

The authors declare no potential conflicts of interest with respect to the research, authorship, and/or publication of this article.

\section{References}

[1] Ferrara, A. (2007) Increasing Prevalence of Gestational Diabetes Mellitus: A Public Health Perspective. Diabetes Care, 30, S141-S146. https://doi.org/10.2337/dc07-s206

[2] Cho, N.H. (2013) Gestational Diabetes Mellitus-Challenges in Research and Management. Diabetes Research and Clinical Practice, 99, 237-239. https://doi.org/10.1016/j.diabres.2013.02.007

[3] Catalano, P.M., McIntyre, H.D., Cruickshank, J.K., McCance, D.R., Dyer, A.R., Metzger, B.E., Lowe, L.P., Trimble, E.R., Coustan, D.R., Hadden, D.R. and Persson, B. (2012) The Hyperglycemia and Adverse Pregnancy Outcome Study: Associations of GDM and Obesity with Pregnancy Outcomes. Diabetes Care, 35, 780-786. https://doi.org/10.2337/dc11-1790

[4] Alberico, S., Montico, M., Barresi, V., Monasta, L., Businelli, C., Soini, V., Erenbourg, A., Ronfani, L. and Maso, G. (2014) The Role of Gestational Diabetes, Pre-Pregnancy Body Mass Index and Gestational Weight Gain on the Risk of Newborn Macrosomia: Results from a Prospective Multicentre Study. BMC Pregnancy and Childbirth, 14, 23. https://doi.org/10.1186/1471-2393-14-23

[5] McGrowder, D., Grant, K., Irving, R., Gordon, L., Crawford, T., Alexander-Lindo, R. and Fraser, Y.P. (2009) Lipid Profile and Clinical Characteristics of Women with Gestational Diabetes Mellitus and Preeclampsia. Journal of Medical Biochemistry, 28, 72-81. https://doi.org/10.2478/v10011-009-0007-x

[6] Hermes, W., Franx, A., Van Pampus, M.G., Bloemenkamp, K.W., Bots, M.L., Van Der Post, J.A., Porath, M., Ponjee, G.A., Tamsma, J.T., Mol, B.W. and De Groot, C.J. (2013) Cardiovascular Risk Factors in Women Who Had Hypertensive Disorders Late in Pregnancy: A Cohort Study. American Journal of Obstetrics and Gynecology, 208, 474-e1. https://doi.org/10.1016/j.ajog.2013.02.016

[7] Jovanovic, L. and Pettitt, D.J. (2001) Gestational Diabetes Mellitus. JAMA, 286, 2516-2518. https://doi.org/10.1001/jama.286.20.2516

[8] Buchanan, T.A. and Xiang, A.H. (2005) Gestational Diabetes Mellitus. The Journal of Clinical Investigation, 115, 485-491. https://doi.org/10.1172/JCI200524531

[9] Vani, K (2015) Alterations of Lipid Profile in Gestational Diabetes Mellitus (GDM) and Type 2 DM Women during Pregnancy. International Journal of Medical Research and Review, 3, 800-804. https://doi.org/10.17511/ijmrr.2015.i8.150 http://medresearch.in/index.php/IJMRR/article/view/351

[10] Leiva, A., Guzman-Gutierrez, E., Contreras-Duarte, S., Fuenzalida, B., Cantin, C., Carvajal, L., Salsoso, R., Gutierrez, J., Pardo, F. and Sobrevia, L. (2017) Adenosine Receptors: Modulators of Lipid Availability That Are Controlled by Lipid Levels. Molecular Aspects of Medicine, 55, 26-44. https://doi.org/10.1016/j.mam.2017.01.007

[11] Herrera, E. and Ortega-Senovilla, H. (2014) Lipid Metabolism during Pregnancy and Its Implications for Fetal Growth. Current Pharmaceutical Biotechnology, 15, 24-31. https://doi.org/10.2174/1389201015666140330192345

[12] Lenin, M., Ramesh, R., Velu, V.K. and Ghose, S. (2017) Association of Dyslipidemia and Glycated Haemoglobin in Gestational Diabetes Mellitus. Journal of Diabetes Mellitus, 7, 275-280. https://doi.org/10.4236/jdm.2017.74022 
[13] Asare-Anane, H., Bawah, A.T., Osa-Andrews, B., Adanu, R., Ofori, E.K., Tagoe, S.B. and Nyarko, A.K. (2013) Lipid Profile in Ghanaian Women with Gestational Diabetes Mellitus. International Journal of Scientific \& Technology Research, 2, 168-175.

[14] Enquobahrie, D.A., Williams, M.A., Qiu, C. and Luthy, D.A. (2005) Early Pregnancy Lipid Concentrations and the Risk of Gestational Diabetes Mellitus. Diabetes Research and Clinical Practice, 70, 134-142. https://doi.org/10.1016/j.diabres.2005.03.022

[15] Butte, N.F. (2000) Carbohydrate and Lipid Metabolism in Pregnancy: Normal Compared with Gestational Diabetes Mellitus. The American Journal of Clinical Nutrition, 71, 1256S-1261S. https://doi.org/10.1093/ajcn/71.5.1256s

[16] Sánchez-Vera, I., Bonet, B., Viana, M., Quintanar, A., Martín, M.D., Blanco, P., Donnay, S. and Albi, M. (2007) Changes in Plasma Lipids and Increased Low-Density Lipoprotein Susceptibility to Oxidation in Pregnancies Complicated by Gestational Diabetes: Consequences of Obesity. Metabolism, 56, 1527-1533. https://doi.org/10.1016/j.metabol.2007.06.020

[17] Howard, B.V. (1987) Lipoprotein Metabolism in Diabetes Mellitus. Journal of Lipid Research, 28, 613-628.

[18] Hollingsworth, D.R. and Grundy, S.M. (1982) Pregnancy-Associated Hypertriglyceridemia in Normal and Diabetic Women: Differences in Insulin-Dependent, Non-Insulin-Dependent, and Gestational Diabetes. Diabetes, 31, 1092-1097. https://doi.org/10.2337/diacare.31.12.1092

[19] Packard, C.J. (2006) Small Dense Low-Density Lipoprotein and Its Role as an Independent Predictor of Cardiovascular Disease. Current Opinion in Lipidology, 17, 412-417. https://doi.org/10.1097/01.mol.0000236367.42755.c1

[20] Khan, R., Ali, K., Khan, Z. and Ahmad, T. (2012) Lipid Profile and Glycosylated Hemoglobin Status of Gestational Diabetic Patients and Healthy Pregnant Women. Indian Journal of Medical Sciences, 66, 149. https://doi.org/10.4103/0019-5359.114175

[21] Herrera, E. and Ortega-Senovilla, H. (2010) Disturbances in Lipid Metabolism in Diabetic Pregnancy-Are These the Cause of the Problem? Best Practice \& Research Clinical Endocrinology \& Metabolism, 24, 515-525. https://doi.org/10.1016/j.beem.2010.05.006

[22] Nolan, C.J., Riley, S.F., Sheedy, M.T., Walstab, J.E. and Beischer, N.A. (1995) Maternal Serum Triglyceride, Glucose Tolerance, and Neonatal Birth Weight Ratio in Pregnancy: A Study within a Racially Heterogeneous Population. Diabetes Care, 18, 50-56. https://doi.org/10.2337/diacare.18.12.1550

[23] Who, E.C. (2004) Appropriate Body-Mass Index for Asian Populations and Its Implications for Policy and Intervention Strategies. The Lancet (London, England), 363, 157. https://doi.org/10.1016/S0140-6736(03)15268-3

[24] Lee, K.W., Ching, S.M., Ramachandran, V., Yee, A., Hoo, F.K., Chia, Y.C., Sulaiman, W.A., Suppiah, S., Mohamed, M.H. and Veettil, S.K. (2018) Prevalence and Risk Factors of Gestational Diabetes Mellitus in Asia: A Systematic Review and Meta-Analysis. BMC Pregnancy and Childbirth, 18, Article No. 494. https://doi.org/10.1186/s12884-018-2131-4

[25] Bronisz, A., Sobiś-Żmudzińska, M., Pujanek, M. and Junik, R. (2007) An Evaluation of Selected Lipid Parameters in Pregnancy Complicated by Gestational Diabetes Mellitus (Part 1). Diabetologia Doświadczalna i Kliniczna, 7, 291.

[26] Kasirajan, S.G., Dakshnamurthy, P., Nachiyar, I., Suthakaran, P.K. and Rajendran, K. (2017) Association of Lipid Accumulation Product with Gestational Diabetes Mel- 
litus: A Hospital Based Study. Annals of Woman and Child Health, 3, A17-A21. https://doi.org/10.21276/AWCH.1461

[27] Zhang, Y., Zhang, H.H., Lu, J.H., Zheng, S.Y., Long, T., Li, Y.T., Wu, W.Z. and Wang, F. (2016) Changes in Serum Adipocyte Fatty Acid-Binding Protein in Women with Gestational Diabetes Mellitus and Normal Pregnant Women during Mid- and Late Pregnancy. Journal of Diabetes Investigation, 7, 797-804.

https://doi.org/10.1111/jdi.12484

[28] Jin, W.Y., Lin, S.L., Hou, R.L., Chen, X.Y., Han, T., Jin, Y., Tang, L., Zhu, Z.W. and Zhao, Z.Y. (2016) Associations between Maternal Lipid Profile and Pregnancy Complications and Perinatal Outcomes: A Population-Based Study from China. BMC Pregnancy and Childbirth, 16, Article No. 60. https://doi.org/10.1186/s12884-016-0852-9

[29] Ertuğ, E.Y., Usta, M., Baytekin, Ö., Diker, V.Ö., Korkmazer, E. anf Özkaya, E. (2016) Serum Lipid Profile and Inflammatory Status in Women with Gestational Diabetes Mellitus. European Journal of General Medicine, 13, 45-52. https://doi.org/10.15197/ejgm.01471

[30] Nusrat-Sultana, M.A., Hasanat, M.H., Yasmin-Aktar, S.P. and Sharmin-Jahan, M.F. (2015) Screening for Gestational Diabetes Mellitus (GDM): Comparison between WHO 1999 and Modified O'Sullivan Criteria. JCD, 2, 13-20.

[31] Sandesh-Panthi, M.A., Hasanat, M.H., Yasmin-Aktar, N.S. and Sharmin-Jahan, M.F. (2015) Frequency of Gestational Diabetes Mellitus in Bangladesh Impact of WHO 2013 Screening Criteria: Efficiency DIPSI \& WHO 1999 Criteria. JCD, 2, 13-19.

[32] Retnakaran, R., Cull, C.A., Thorne, K.I., Adler, A.I. and Holman, R.R. (2006) Risk Factors for Renal Dysfunction in Type 2 Diabetes: UK Prospective Diabetes Study 74. Diabetes, 55, 1832-1839. https://doi.org/10.2337/db05-1620

[33] American Diabetes Association (2015) Standards of Medical Care in Diabetes-2015 Abridged for Primary Care Providers. Clinical Diabetes: A Publication of the American Diabetes Association, 33, 97. https://doi.org/10.2337/diaclin.33.2.97

[34] Koivunen, R.M., Juutinen, J., Vauhkonen, I., Morin-Papunen, L.C., Ruokonen, A. and Tapanainen, J.S. (2001) Metabolic and Steroidogenic Alterations Related to Increased Frequency of Polycystic Ovaries in Women with a History of Gestational Diabetes. The Journal of Clinical Endocrinology \& Metabolism, 86, 2591-2599. https://doi.org/10.1210/jcem.86.6.7612

[35] Amraei, A. and Azemati, M. (2007) Metabolic Status of Women with Gestational Diabetes Mellitus Six Months after Delivery. Research Journal of Biological Sciences, 2, 104-107. 